Las memorias del deseo.

Aproximaciones al consumo cultural desde los públicos del cine erótico en Argentina (1960-1970)

Ailin Basilio Fabris

DOI: https://doi.org/10.24215/16696581e253

\title{
Las memorias del deseo
}

Aproximaciones al consumo cultural desde los públicos del cine erótico en Argentina (1960-1970)

\section{Desire memories}

Approaches to cultural consumption practices on erotic cinema from the audiences perspective in Argentina (1960-1970)

\author{
Ailin Basilio Fabris ailinbasiliofabris@gmail.com \\ https://orcid.org/0000-0001-9140-5932 \\ Universidad Nacional de Quilmes, Argentina
}


Ailin Basilio Fabris Las memorias del deseo Aproximaciones al consumo cultural desde los públicos del cine erótico en Argentina (1960-1970)

\section{Resumen}

El artículo examina el consumo cultural del cine erótico en la década de los sesenta a fin de rastrear sentidos, representaciones y prácticas que permitan reconstruir los procesos de conformación de la identidad de género y la sexualidad en Argentina, en perspectiva histórica y de género. En función de relatos orales recopilados, la premisa que sostiene este trabajo consiste en proponer a las prácticas de consumo como terreno para la articulación y producción de sentidos y nociones sobre la subjetivación de la sexualidad en marcos históricos caracterizados por el autoritarismo político y la censura. A su vez, se aborda la dimensión generacional como un constructo social e histórico que signó, entre otras cosas, la configuración de la memoria, y al mismo tiempo que inquiere la dimensión generizada de tales dinámicas.

Palabras Clave: consumo; sexualidad; erotismo; Isabel Sarli

\section{Abstract}

The paper analyses the cultural consumption of erotic cinema during the sixties and seventies in order to track down practices, representations, and senses that allow the reconstruction of gender identity and sexuality processes in Argentina from a historical framework and gender studies. Using oral testimonies the paper considers cultural consumption practices as a field that articulates and produce senses and notions around sexual subjectivities during state censorship and political authoritarism. In addition, the paper deals with the problem of generation as an analytic category that signalized the arrangement of memory.

Keywords: consumption; sexuality; eroticism; Isabel Sarli 
Ailin Basilio Fabris Las memorias del deseo Aproximaciones al consumo cultural desde los públicos del cine erótico en Argentina (1960-1970)

\section{Introducción}

En una imagen publicitaria de 1969, el curvilíneo cuerpo de la actriz Isabel Sarli (1936-2019) ocupaba la imagen central en la promoción de su nuevo filme ${ }^{1}$. Esta situación no resultaba de ninguna manera insólita debido a que, desde su debut cinematográfico en el año 1957, su rostro, sus senos y sus voluptuosas curvas fueron asociados a formas de interpelar espectadores.

Diversos hechos se producían dentro y fuera de las salas de cine en cuanto sus películas se estrenaban en el circuito local. Desde desmayos o acalorados recibimientos, la figura de Sarli gozó de enorme popularidad y reconocimiento en sus más tres décadas de actividad cinematográfica $^{2}$. Nacida en la provincia de Entre Ríos, pero trasladándose a temprana edad a la Ciudad de Buenos Aires, Isabel Sarli desarrolló una carrera profesional fructífera producto del éxito y la masividad que sus películas adquirían a los ojos del público y del fetichismo que, Armando Bo, el director, cultivaba para con ella. En un marco de sociabilidad heterosexual, sus películas eróticas filmadas procuraron diseminar imágenes, sentidos y representaciones ligadas al sexo, al placer y que, a contrapelo, instalaron narrativas pedagógicas en las que la violencia ocupó un lugar central a la hora de significar las sensibilidades de género en aquel entonces.

En lo que refiere al cine erótico, definir las características y contornos no resulta tarea sencilla. La relación entre Bo y Sarli duró más de tres décadas, de 1957 a 1981, se cristalizó en 27 filmes y en una centena de giras transnacionales. Pero, ¿qué los hizo erótico? ¿Por qué considerarlo una producción y una experiencia sociocultural ligada a la sexualidad? Su premisa principal fue el protagonismo de un cuerpo femenino exuberante y atractivo, traduciéndolo, conforme avanzaba en popularidad, en un objeto erógeno a un sujeto sexual activo que revelaba y escondía, interpelaba al espectador y sostenía la previsibilidad con lo insospechado (Barthes, 2008; Williams, 2008)

En este trabajo nos abocamos a analizar el impacto que el cine erótico produjo en sus espectadores sobre la base de relatos orales que nos permitan reconstruir sus experiencias en tanto conforman procesos de consumo cultural. En este sentido, problematizamos el alcance y la significación que el consumo de este bien cultural concitó en tanto fenómeno social y cultural vinculado a la producción de disposiciones en torno al género y la sexualidad desde una mirada histórica.

\footnotetext{
${ }^{1}$ La gaceta de espectáculos, 16 de febrero, 1969.

2“Isabel Sarli prende fuego los cines”, 6 de octubre de 1971, Diario Crónica. 
A diferencia de otros abordajes en los que se privilegió su arista cinematográfica (Capalbo \& Valdéz, 2004; Braslavsky, Drajner Barredo \& Pereyra, 2013; Drajner Barredo, 2016) este trabajo explora el vínculo forjado entre esta instancia cultural erótica y sus consumidores a partir de interrogarse cómo su consumo en las salas de cine habilitó procesos, prácticas y dinámicas para la elaboración de percepciones, nociones y experiencias ligadas a la sexualidad y al género. Asimismo, aspira a bosquejar al erotismo, al deseo y a la sexualidad como problemas analíticos de importancia para las ciencias sociales.

El recorte temporal responde no sólo a los ciclos de vida de este proyecto cultural, sino además centra tal al consumo sobre la base de que estos espacios oficiaron como enclaves para la valorización y la significación social y cultural del género en un escenario histórico signado por violencias morales en las que la sexualidad fue complementaria de una metáfora de orden y control social (Simonetto, 2016). De esta manera, construir modelos de estado y ciudadanía supone prescribir y dispensar correlatos sobre el ejercicio, desplazamiento y comportamientos de las sexualidades.

El punto de partida para analizar estas transformaciones ha sido las condiciones de emergencia de cierta sensibilidad social y cultural articulada a la problematización de la sexualidad en la década de los sesenta (Cosse, 2010; Felitti, 2012). A su vez, el artículo avanza sobre el horizonte cultural, social y político de la década de los setenta y cómo el consumo cultural del erotismo aglutinó un conjunto de ansiedades y experiencias ligadas a una gradual construcción de otros órdenes de género concomitantes a un Estado que cribaba sus propias narrativas sobre la sexualidad, la familia y la moral en función de estrategias de gobernabilidad (D’Antonio, 2015). Así, estas coordenadas abonan a reflexionar sobre los sesenta y los setenta como períodos inextricables y ambivalentes en los cuales la sexualidad ostentó un rol central concomitante y trasversal a los planos políticos, económicos, culturales y sociales de sendos decenios.

Asimismo, este trabajo pretende contribuir a la construcción de un campo disciplinar. En primer lugar, a los trabajos en torno al consumo y género en perspectiva histórica (De Grazia \& Furlough, 1996; Hollows, 2000; Caldo, 2016; Pite, 2016; Pérez, 2017). En segundo lugar, a las investigaciones que imbrican memoria, género y sexualidad (Parrini \& Brito, 2014). A partir de un trabajo de búsqueda y relevamiento de testimonios orales de mujeres y hombres que concurrieron al cine a consumir las películas eróticas de Sarli y Bo, el artículo procura repensar cómo estas experiencias operaron como prácticas de consumo, es decir, procesos de producción y despliegue de valor y significación que coadyuvaron a la subjetivación y el reordenamiento de ciertas disposiciones de género en un determinado momento histórico, al 
Ailin Basilio Fabris Las memorias del deseo Aproximaciones al consumo cultural desde los públicos del cine erótico en Argentina (1960-1970)

mismo tiempo que discurre sobre los agenciamientos y las distintas rúbricas que la sexualidad detentó en la segunda mitad del siglo XX en Argentina.

Para ello, el trabajo se organiza en tres apartados. El primero, se enfoca en la lectura interdisciplinaria del consumo y su lente fecunda para la investigación histórica. En segundo lugar, se adentra en los relatos que distintos consumidores realizaron alrededor del cine erótico y la figura de Sarli a partir de vectores relacionados a una dimensión generacional y las dinámicas activas de la memoria. Finalmente, profundiza cómo las instancias de consumo permitieron resignificar en los sujetos aspectos ligados a la construcción de identidades y subjetivaciones de género y sexualidad. Las conclusiones proponen bosquejar posibles derroteros que profundicen la tríada consumo, género e historia.

\section{El consumo: perspectivas, problemas y abordajes}

Desde la perspectiva de las ciencias sociales, la categoría de consumo ha estado largamente sujeta a indagación, monopolizada principalmente por la economía, siendo la historiografía más reciente. En consecuencia, frente a un fraccionamiento disciplinario, el desafío consiste en pensar de forma articulada y dinámica la intersección cultural y social de ciertos bienes, su circulación, su valorización y su significación (Appadurai, 1991), prestando especial atención a su dimensión generizada.

En esta dirección, los primeros esbozos vernáculos relacionados con el rol del consumo se plantearon en el último tercio de la década de los noventa (Rocchi, 1998) a través de una orientación de la historiografía económica. En los últimos años, este interés no sólo se amplificó, sino que se diversificó en función de abordar ciertos períodos y procesos históricos desde diversos vectores y sujetos, como la comida, la publicidad, la infancia, el automóvil, el peronismo y los lectores, entre otros (Elena 2011; Milanesio, 2014; Sheinkman, 2017) o avanzar en la proposición de nuevos objetos de estudio (Caldo, 2013; Pite, 2016; Guy, 2018; Mitidieri, 2018). La proliferación del consumo como prisma analítico, sin embargo, se circunscribió a abordajes urbanos.

En lo que refiere a su valorización y significación cultural, el consumo cultural se arraigó como prisma analítico en los umbrales de fin del siglo pasado en América Latina. Esta perspectiva procuró interrelacionar objetos, bienes y agentes bajo el supuesto de que ellos son desplegados bajo condiciones estructurales de desigualdad en los que el cine, la música, la lectura, el esparcimiento, entre otros, permiten. Sus principales centros de producción emergieron en México (Mantecón, 2002, 2008) y Argentina (Wortman, 2012, 2015, 2018). Recuperando y advirtiendo que el consumo no sólo ha adquirido una densa circulación en el 
Ailin Basilio Fabris Las memorias del deseo Aproximaciones al consumo cultural desde los públicos del cine erótico en Argentina (1960-1970)

campo historiográfico, sostenemos al consumo cultural «como el conjunto de procesos de apropiación y usos de productos en los que el valor simbólico prevalece sobre los valores de uso y de cambio, o donde al menos estos últimos se configuran subordinados a la dimensión simbólica» (García Canclini, 1999, p.42).

Esta definición desestima un análisis concluyente y homogénea en la interpretación de las diversas prácticas y dinámicas que hacen al consumo un prisma analítico, pero también un constructo histórico cuya permuta oscila en las diversas redefiniciones y reformulaciones que los procesos y los agentes históricos realizan en torno a él. Entonces existe una noción de producción vinculada a la vivencia, la interpretación y la valorización que los sujetos hacen de objetos, discursos, dispositivos y sentidos en un determinado momento histórico. Este marco conceptual nos permite ponderar y rastrear una concepción más amplia de la categoría consumo-dinámica, flexible- en la que debemos incluir e insertar la perspectiva de género.

Como indica Trentman (2004), el viso histórico que constituye al consumo supone abordarlo como un constructo social relativamente reciente que nos permite identificar y revisar un repertorio de relaciones, nociones y prácticas pretéritas a partir de una lente fluida, negociada y abierta a disputas por sus sentidos y significaciones en las que ejes como el género, la etnia y la clase operan en su estructuración e intelección. De esta manera, las prácticas y sentidos fungidos en el consumo cultural suponen un uso diferenciado y diferenciador en la que el género opera como una lógica central ligada a la propia constitución e interpretación de la identidad y las subjetividades en el marco de una expectativa social diferenciada entre varones y mujeres.

Pero también la variable generacional tiene incidencia en los análisis de consumo. Los testimonios que conforman nuestro corpus oral han sido narrados, en un gran porcentaje, por hombres cuya experiencia ha sido marcada por la inscripción social de la adolescencia. En pos de su interpretación, la noción de generación resonaba con fuerza debido a lo que recientes trabajos historiográficos evidenciaron alrededor de la sociabilidad y las experiencias juveniles como sinergia para comprender los marcos de entendimiento y materialidad de acontecimientos y períodos puntuales en el transcurso del siglo XX (Cammarota, 2014; Manzano, 2017).

Teniendo en cuenta estas consideraciones, el marco conceptual de la historia oral captura y repone los relatos e interpretaciones respecto a un aspecto de un pasado todavía en construcción (Schwarzstein, 2002), lo que supone pensar que la memoria es un proceso abierto, histórico y librado a las batallas por su significación y agenciamiento (Jelin, 2002). En este sentido, todo registro es una instancia mediada por una amplia gama de dimensiones y 
actores dentro de un contexto determinado, empujando a los cientistas sociales a recuperar y ubicar en tiempo y espacio cada una de estas narrativas (Bjerg, 2012; Portelli, 1981).

Por ello, amalgamar los estudios sobre consumo cultural, género y sexualidad, generación e historia oral, nos permite arrojar luz sobre los marcos de interpretación, nociones y prácticas que dieron sentido a las narraciones sobre el público del cine erótico en las décadas de los sesenta y setenta. Asimismo, esta palestra de perspectivas problematiza los procesos de configuración de una subjetividad anudada a la proximidad que este consumo fundaba con la sexualidad y el cuerpo. Explora las formas de resignificar los bienes culturales bajo nociones y prácticas posibles de encarnar y canalizar la construcción de la identidad en su articulación con la sexualidad.

La especificidad que sostiene a las tramas eróticas de este cine estriba en la significación y la representación sobre el sexo, el erotismo y el goce presente y activado en estos arreglos culturales. Las relaciones entre memoria, deseo y sexualidad nos permite pensar las memorias de la sexualidad como productos y actos en los que convergen procesos políticos, sociales, identitarios y culturales, emociones y afectos, discursos y cuerpos (Parrini \& Brito, 2014) ${ }^{3}$.

El problema de cómo hablar sobre la sexualidad se encuentra mediado por un discurso heterosexual que se impone como universal, ahistórico y natural, configurando toda una urdimbre de sentidos, discursos y prácticas sedimentadas y revestidas de un carácter binario que apela y alega diferencias naturales entre hombres y mujeres, a la vez que constituye esta división dicotómica como prerrogativa para el ordenamiento y cognoscibilidad del universo social (Bourdieu, 2000).

El corpus heurístico está conformado por un conjunto de relatos orales. Durante 2018 se realizaron una serie de entrevistas en profundidad con el fin de conocer cómo, después de casi medio siglo, se recuerda y resignifica una experiencia formativa como la del cine erótico en Argentina. Al mismo tiempo se señala que, a pesar de la pregnancia de voces masculinas heterosexuales, esa disparidad de género opera indiciariamente para preguntarse qué formas y prescripciones existieron alrededor de lo femenino y la sexualidad en aquellos años.

\footnotetext{
${ }^{3} \mathrm{~A}$ pesar de partir de una matriz heteronormativa, tanto el cine erótico como la evocación de su consumo se encuentran abiertos a disputas y procesos de resignificación. De ninguna manera este trabajo clausura dicha posibilidad, sino que advierte que esas divergencias en su reapropiación instalan el interrogante por otros modos de subjetivar durante y posteriormente a ese período histórico. 
Ailin Basilio Fabris Las memorias del deseo Aproximaciones al consumo cultural desde los públicos del cine erótico en Argentina (1960-1970)

\title{
Relatos, género y memoria
}

A través de la historia oral, se reconstruyen y reponen las prácticas y sentidos subjetivos que signaron una etapa en la vivencia y construcción de modulaciones acerca de las relaciones entre cuerpo, género y sexualidad. Esta tríada permite problematizar los procesos de inscripción de la memoria en el cuerpo, su cariz generizada y cómo se modifica a la luz de los diferentes regímenes políticos, culturales y de género.

R., un hombre de 72 años, nació en 1945 y fue a ver al cine la primera película de la dupla, El trueno entre las hojas, cuando tenía 17 años de edad en el año 1962 en un reestreno en un cine de barrio de la zona sur del Gran Buenos Aires:

\begin{abstract}
Yo tenía 17 años y entré de contrabando porque no podía entrar hasta los 18 años, eran películas prohibidas, entonces tuve que hacer un truco para poder entrar en el cine porque en ese tiempo había mucho más control [...] en cine sólo vi esa, había muchas, pero en la televisión y ya estaban cortadas.

¿Te acordas de esa experiencia? ¿De ese momento?

La experiencia de todo chico que le atrae lo prohibido, te das cuenta, le emociona lo prohibido y más cuando es del sexo opuesto, son experiencias de unos adolescentes que quieren ver algo que está prohibido. De repente, quizás cuando está permitido, ya ni le da bolilla, pero lo prohibido siempre es mucho más atractivo para esa edad (Testimonio de R.,varón, 72 años)
\end{abstract}

En el interregno que separa este primer acercamiento y su consumo bajo el formato televisivo en la década de los ochenta y noventa, R. pareciera como suspendido en el tiempo por cuanto el marco de la televisión por aire, y posteriormente por cable, se interpreta como una habilitación social y cultural más amplia para narrar sobre su experiencia como espectador.

En concomitancia, en el relato organizado por C., un varón de 55 años, la cuestión de la sexualidad se transformaba en un elemento nodal en la constitución de lo adolescente de la época; encontraba en el cine erótico una forma de instituir un saber, a la vez que canalizar una pertenencia y una sociabilidad masculina.

\begin{abstract}
¿Cómo nos sentíamos? Era lo único que veíamos. No había pornografía, no había nada. No había celulares, no había computadoras. Vos pensá que somos hombres. Como todo hombre adolescente te cuentan "Mira yo tuve...". Mentira. Éramos pibes; yo tuve experiencias. Era saber quién era el más mentiroso en esa época. Entonces cada uno viste, sabíamos que estaban las películas de Isabel Sarli, éramos todos pibes y bueno. Yo tenía un tío que trabajaba en el Cine Rex de Berazategui, que ya no está más, y se iba a ver las películas de Isabel Sarli, con un amigo; íbamos todos. Yo tenía la suerte de poder entrar gracias a mi tío. Tenía 16 años más o menos, pero no podías, eras menor, entendes.
\end{abstract}


Tratábamos de ir bien vestidos, peinaditos, arreglados, con gomina. Entonces era ir a ver... la señora mostraba los senos, nada más; era como una fantasía. No era como si fueses a ver pornografía, porque no era pornografía. No había. Era una época difícil que acá no entraba nada. Durante la época de los milicos fue todo más jodido; se prohibía mucho. Vos pensá que ella estaba casada con Armando Bo y ellos filmaban todas las películas en Paraguay, porque acá no se podía. En todos los argumentos ella prostituta. Hay una escena de una película que ella dice “¿Qué pretende usted de mí?”. Carne, Fiebre, Fuego, Una mariposa en la noche.

Al evocar estas experiencias, para C. ir al cine a ver las películas de Sarli significó el comienzo de una aproximación hacia el sexo y la sexualidad. Al referirse a Isabel con el término Señora, le confería alícuotas de afecto mediada por el respecto y jerarquías sociales.

Esa interpretación que emanaba de C., reverbera en al menos dos relatos más de nuestro corpus. Por un lado, la idea de su atractivo y la fascinación que despertaba en las audiencias, en especial las masculinas, en términos de cristalizar una experiencia transversal a todos los espectadores, homogeneizando una idea de masculinidad heterosexual en ascenso. Por otro lado, consignarles a las películas una función de disrupción y desafío a las normas del momento. Ambas dimensiones convergen en la asimilación e interpretación de su experiencia de consumo como parte de una época, como un horizonte común en el sentir y en el encarnar la sexualidad, en especial de las audiencias lozanas, las cuales podían encontrar en la actriz modos de canalizar mandatos y expectativas.

H. recuerda que en la década de los setenta concurrió a un cine aledaño para ver una película erótica de Isabel Sarli. Allí, la administración de su cuerpo fue clave en tanto supuso enaltecer y ejercitar una masculinidad, cuya construcción descansó en habitar una virilidad corporal heterosexual.

En el año 1974 o 1975, después de ser mayor de 18 años porque antes no te permitían entrar al cine. La entrada estaba controlada, según la cara pedían documento o no. Podías decir que tenías 18 pero la cara te decía que no, entonces era normal que pidiesen documentos en ese momento antes de entrar a la sala.

¿Era accesible ir al cine en ese momento?

No me acuerdo de un precio, pero para la época era accesible. Si nos ponemos a pensar que para el momento éramos estudiantes secundarios y nuestras salidas al cine se daban una vez que terminábamos de estudiar, así de pasada quizás íbamos al cine. Siempre nos manejábamos en un grupo de adolescentes, éramos todos de la misma edad. Lo normal era salir del colegio un jueves o un viernes, ir al cine.

La idea de lo colectivo contrasta con lo expresado por R., que reinterpretaba lo prohibido como un elemento de interpelación, de invitación al cine. En este sentido, lo polisémico de lo prohibido operaba como una práctica a través de la cual se trasgredía simbólicamente un estatuto de sociabilidad a la vez que oficiaba como un rito de iniciación a la adultez, poniendo 
Ailin Basilio Fabris Las memorias del deseo Aproximaciones al consumo cultural desde los públicos del cine erótico en Argentina (1960-1970)

en cuestión los límites discursivos y materiales de lo prohibido. Ambos relatos develan una intermitencia en ese pasaje hacia una noción de adulto anudada a lo prohibido, reforzando el carácter y el sustrato masculino de tal estatuto. En la idea de ir en un grupo se anudaba a un ethos endilgado a fortalecer un proceso de cofradía masculina en la cual se forjaba la ritualidad de lo adulto al mismo tiempo que oficiaba de una iniciación a lo sexual. En ese sentido, el consumo colectivo se inscribe en una amplia gama de prácticas ligadas a la masculinidad y al sexo: consumir servicios sexuales propició el reconocimiento de lo viril y la vigorosidad entre pares (Simonetto, 2018).

En cuanto a la pregunta por el nombre de las películas que $\mathrm{H}$. había visionado durante su adolescencia, su relato porta una demarcación importante: «Carne, Fiebre, Fuego...esas son las que quizás más retengo. Otras las he visto y quizás no me acuerdo. No soy muy adicto a ese tipo de filmografía, pero en ese momento era una aventura para nosotros. Una picardía».

La idea de adicción insinuó una disonancia entre su rememoración de adolescente y el relato oral frente a mí, buscando trazar una distancia, una lejanía entre sus prácticas lozanas y su presencia física como padre de familia en la actualidad. De manera similar, los críticos de cine que reseñaban las películas eróticas de Bo caracterizaban de esta manera, de adictos, a quienes las consumían, bosquejando un imaginario social en el cual se tramaba una correlación entre la adicción, en un sentido peyorativo, y el origen social de los espectadores, nutriendo una constelación de ideas sostenidas en base al presupuesto de que la adicción deviene de la pertenencia a un tipo ideal de clase social de menores recursos económicos, baja escolaridad y una sociabilidad endogámica. En esa noción de adicción, posiblemente H. lo asociaba con los sentidos que circulan sobre la pornografía y las consecuencias u efectos que produce en quienes la visionan y consumen asiduamente. Por otro lado, el significado sociocultural de las prácticas sexuales de estos jóvenes se veía encuadro e inscrito en escenarios y dinámicas de discusión sobre la sexualidad, el disfrute y la sociabilidad entre hombres y mujeres. En mayor o en menor medida, los discursos médicos, religiosos, políticos y científicos buscaban hacer de la sexualidad un eje desde cual poder regular, encauzar y expedir ciertas nociones, expectativas, códigos y saberes en las tribunas de diarios, revistas, libros e instituciones.

En el marco de la entrevista, la risa oficiaba como una válvula para flexibilizar y disipar la densidad del aire y la atmósfera que imbuía al encuentro. El maridaje entre risas nerviosas y la construcción de una narración signada por la demarcación entre el yo de ayer y el yo que construyo mediante la oralidad, aportaban un indicio de la renuencia y a la vez la complejidad de narrar y revisitar eventos enraizados con el sexo y la sexualidad frente a mi posición como joven entrevistadora:

Question, Vol. 1, N. ${ }^{\circ} 65$, abril 2020. ISSN 1669-6581

Instituto de Investigaciones en Comunicación | Facultad de Periodismo y Comunicación Social | Universidad Nacional de La Plata La Plata | Buenos Aires | Argentina

Página 10 de 24 
Ailin Basilio Fabris Las memorias del deseo Aproximaciones al consumo cultural desde los públicos del cine erótico en Argentina (1960-1970)

Vos ponete a pensar que yo, siendo hombre y adolescente, era una atracción por así decirlo para nosotros. En ese momento, que se yo, era algo innovador para nosotros y también para la época presenciar así desnudos en cine o algo, cosa que no se veía mucho a comparación de hoy en día (H., varón, 61 años)

En la interpelación y fisionomía de las audiencias, el cine erótico de Bo apelaba a una noción de masculinidad amplia y heterogénea en la que se pudiera agrupar un repertorio de varones cuyas diferencias etarias se diluyesen bajo el manto de oscuridad y anonimato en las salas. Lo prohibido consistía en una estrategia retórica que se tornaba eficaz en tanto propiciaba una atracción y articulaba una dualidad, hombre-desnudo, como natural y consustancial de la identidad masculina. El reclutamiento de hombres, no obstante, no comprendía una exclusión material de lo femenino, pero sí un letargo simbólico en su inclusión para películas eróticas. La figura femenina por antonomasia, Isabel Sarli, se convertía en un objeto/sujeto sexual deseado por las analogías entre la cámara y el ojo del espectador, la excitación de los personajes como representación de una universalidad masculina encarnable y reproducida por los espectadores hombres:

Estaba chico yo, pero recuerdo que la mayoría eran gente grande, muy pocos chicos había. Los más vagos, de repente eran los que podían ir. Los que vagaban más, pero la mayoría era gente grande la que iba a ver eso. La mayoría hombre esos, a veces pareja, pero la mayoría eran hombres solos que iban a ver eso (R., varón, 72 años)

En el relato de $\mathrm{H}$., en cuanto la pregunta por la composición del público que asistía, recordaba cómo las salas de cine se veían concurridas por estudiantes secundarios de las escuelas de la zona: «Era tranqui, dentro de todo. Mayormente éramos hombres y adolescentes que salíamos de las escuelas secundarias, no éramos los únicos que íbamos. No iban muchas parejas» Por otro lado, M., un varón de 54 años, relata que con 14 años asistió a la proyección de Carne en la década de los setenta.

La primera película de Sarli la habré ido a ver a los 14 años. Era Carne Éxtasis y Tropical, daban dos películas. Había dos otros cines, no se podían ver; en Quilmes había posibilidad de verla, pero si eras menor no te dejaban, no podías entrar. Se suponía que eran películas para mayores. No me acuerdo si mayores de 16 o de 18 años, pero no podías entrar. Había cines como... Había un cine en Bernal, no me acuerdo cómo se llamaba, que íbamos a ver esas películas y en realidad entrabas medio clandestinamente y estaba lleno de pibes de mi edad, no había mucha gente grande. Después había cines como El Colonial, que es un cine teatro, donde daban esas películas, abajo del puente. En Quilmes creo que también daban alagunas películas de 
Isabel Sarli pero no te dejaban entrar, era más difícil entrar. En el Monumental de Bernal, ya está, me acordé, pero no existe más.

¿Qué recordás de ese momento en esos cines?

¿Qué me acuerdo como significativo? Me acuerdo que tenía que ver con que estaba censurado; en ese momento no había demasiado acceso a ver ese tipo de cine y a ver cuerpos desnudos y digamos...no había siliconas, no había nada. Isabel Sarli era el hito de todo lo que fue después ese cine que tenía que ver con lo erótico porque no había ninguna escena, no había genitalidad, se le veían los pechos a Isabel Sarli y nada más. La parte de abajo no se veía, no se veía absolutamente nada. Estaba cruzada de piernas, digamos, pero nunca se veía más allá de los senos que yo me acuerde. Eso estaba exacerbado ya porque había escenas que duraban un montón de tiempo donde ella, digamos, estaba largo tiempo masajeándose sus senos. Entonces, me acuerdo eso como significativo, de que no existía, de que no lo podías ver en otro lugar, todo muy censurado, algo que tuviese que ver con eso. Después aparecieron revistas, en los ochenta, mujeres con menos ropa. Pero tiene que ver con mi adolescencia, con toda una...un momento de despertar sexual, con un momento de cosas que tienen que ver en ese sentido.

Me acuerdo eso, de ver muchos pibes, de ver muchos pibes de nuestra edad. Inclusive nos rateábamos de la escuela e íbamos al cine, pasábamos clandestinamente. Le dábamos alguna propina al acomodador. Había un tipo con una linterna que te acomodaba, entonces le dabas una guita y entrabas por ahí. Eso creo que en Quilmes no se podía hacer, era más difícil. Pero estamos hablando ya empezada la dictadura, eso también marca como algo (M., varón, 54 años)

En los testimonios auscultados, los entrevistados le imprimieron un carácter generacional al cine erótico y a su consumo. El uso del tiempo pasado no sólo indica que se buscaba tramar una diferencia entre el yo de mi adolescencia con ese yo actual adulto que relata, sino que es esa misma distancia un modo de reactualizar la memoria, su interpretación y su significado. A medida que $M$. cuenta con mayor soltura su experiencia, un halo de inhibición, una combinación de cierta vergüenza con cohibición, se destilaba del ejercicio de recordar y construir un relato. La hexis corporal de algunos entrevistados develaba los cambios y los movimientos de acuerdo a las preguntas realizadas, es decir, el acto de relatar estaba acompasado por ciertas gestualidades y ademanes corporales que denotaban diferentes emociones y estrategias de comportamiento a luz del tipo de preguntas propuestas. A esto se le añadía las reformulaciones y los balbuceos en el momento de definir y enunciar ciertas palabras, inclinaciones que fueron diluyéndose a medida que el intercambio avanzaba.

En la autopercepción de M. sobre su inicio sexual a través de las películas eróticas, esto se extendía a sus otros compañeros, tramando lazos de solidaridad para lograr entrar a los cines. A la vez que las películas y la figura de Isabel Sarli se convertían en un primigenio alumbramiento respecto del cuerpo femenino a los ojos de lozanos muchachos, ésta se acoplaba con la oscuridad de los auditorios para coadyuvar en la producción de un autodescubrimiento del placer, de lo erógeno, en la materialidad corporal masculina. La 
Ailin Basilio Fabris Las memorias del deseo Aproximaciones al consumo cultural desde los públicos del cine erótico en Argentina (1960-1970)

sinergia entre la iniciación y la pedagogía daban lugar al aprendizaje y a la configuración de la masculinidad juvenil, como un fenómeno de ritualidad de pasaje hacia una sexualidad concebida como adulta. De la oralidad no se desprende una traslación directa entre ver y consumir este cine a una encarnación en prácticas sexuales, sino que hemos de recuperarlas y reponerlas en los marcos de un proceso cultural de construcción de la sexualidad en la que los dispositivos tecnológicos operan como productores y basculan interpretaciones históricas específicas sobre el sexo y el género.

Al formular una pregunta por el significado del cine erótico, O. se mantiene dubitativo por algunos instantes sopesando qué responder y cómo enunciarlo. Ese silencio inaugural no sólo devela el acto de repensarse uno mismo dentro de ese recordar, sino también de hacer legible, y enunciable, una narrativa ligada a la sexualidad:

Me remonta a cuando yo era adolescente, lo prohibido de una época para cuando yo era adolescente. Así que era toda una aventura a ver algo de ellos, más que de Armando Bo, de ella. Así que la prohibición...Yo en esa época tenía 16 años, en 1973, cuando venimos a vivir a La Plata, así que era lo prohibido para un adolescente y como la filmografía era para mayores de 18, era transgredir para poder llegar a ver [...] claro, tenía el sabor de la aventura. Más allá del erotismo, de la fantasía del muchacho. También había muchos chistes sobre Isabel Sarli, era el ícono del momento.

Quisiera imaginarte a vos en ese cine viendo las películas.

Faltando al colegio, era toda una cuestión de decir la rebeldía en su máxima expresión. Y la complicidad del boletero. El tipo sabía que éramos chicos, que esto y lo otro. Todos varones, todos varones en el Cine Roca de La Plata, que ya no existe más, que era el cine que pasaba las películas eróticas y bueno, siempre había algo de Isabel Sarli. Era el lugar a donde los pibes queríamos ir.

Cuando vos decís "Todos hombres", ¿eran un grupo?

Íbamos con mis amigos. Siempre tuve unos amigos, éramos dos o tres que íbamos juntos. Yo nunca fui solo; sólo nunca fui. Uno para tomar coraje necesitaba tomar alguna complicidad y si después decías "Fui solo", no te creían. Entonces, yo ahora me doy cuenta de todo eso, pero era así. Cuando ibas a hacer alguna macana, entre comillas, no lo hacías sólo, te daba coraje hacerlo con alguien más. Como fumar, por ejemplo, o ir a bailar. Siempre tenía esos amigos con los que salía a hacer estas aventuras. Toda muchacha, por el horario también. Yo iba a la tarde al cine, a ver esas películas. Nosotros íbamos temprano, a la tarde; no íbamos de noche. Yo de no podía... entresemana no salía porque mis viejos me iban a decir "¿qué estás haciendo? ¿A dónde vas?". La idea era faltar al colegio e ir al cine. Yo no iba solo a ver a Isabel Sarli, porque el Cine Roca era el cine prohibido para esa edad.

En los relatos de los consumidores masculinos que hemos pernotado, la idea recurrente de asociar adolescencia con lo prohibido cobra fuerza en tanto la primera se significa como un estadio en la construcción de la propia identidad como masculina y adolescente. Los trabajos sobre la noción de juventud han abordado el fenómeno de lo juvenil como un aspecto generacional atado a un mercado cultural diversificado y en crecimiento, por un lado, y a los

Question, Vol. 1, N. ${ }^{\circ}$ 65, abril 2020. ISSN 1669-6581

Instituto de Investigaciones en Comunicación | Facultad de Periodismo y Comunicación Social | Universidad Nacional de La Plata 
Ailin Basilio Fabris Las memorias del deseo Aproximaciones al consumo cultural desde los públicos del cine erótico en Argentina (1960-1970)

fenómenos políticos y sociales bajo los cuales florece una pertenencia juvenil a ciertos espacios ideológicos, por el otro'. La dimensión etaria para definir los alcances de lo juvenil, el significado de la edad en la delimitación de la juventud frente a la adultez, resultan de enorme importancia frente a la historización de prácticas que se leen en clave generacional. En las investigaciones sobre sexualidad adolescente, la idea de iniciación sexual se hace mucho más presente e imperativa en hombres que en mujeres, correspondiéndose a un modelo/rol de masculinidad a cumplimentar que prescribe una edad y la conformación de un saber respecto al sexo y la sexualidad que varía de acuerdo a la clase y a las estructuras sociales de cada sociedad (Pantelides y Manzelli, 2003, 2007).

En sus investigaciones respecto a la especificidad en la relación adolescente-sexualidad en Argentina, Daniel Jones explora cómo la iniciación sexual, primera relación sexual o debut sexual son fenómenos sociales y culturalmente construidos que se corresponden a construcciones culturales respecto de los esquemas de género y la sexualidad estructurantes dentro de una determinada coyuntura histórica (2010b, 2010c). Por otro lado, el lugar de la pornografía dentro de esos arreglos culturales de iniciación y primera relación sexual se presenta como ambivalente y contradictoria respecto de la realidad por cuanto sus representaciones no se corresponden en su totalidad con las disposiciones y la sociabilidad entre hombres y mujeres, a la vez que se conforma como parte de un aprendizaje y conocimiento sobre el cuerpo femenino y el placer para los hombres (2010a).

Sin embargo, haciendo a un lado una discusión ontológica sobre la pornografía y el erotismo, si las películas de Bo y Sarli eran de las primeras o de las segundas, entendemos que el surgimiento, la circulación y el consumo de estos bienes culturales revelan las mediaciones, registros y marcos sociales y culturales sobre la significación y la representación de la sexualidad, el placer y el erotismo en las hendiduras y las dinámicas de ciertos actores sociales y enclaves de la segunda mitad del siglo XX. De ello se deduce que el lugar asignado por estos consumidores al acceso de una oferta cultural, ligada a imágenes, sentidos y nociones de erogenia, sexualidad y erotismo, resultaba novedosa y a la vez atractiva. En sus marcos interpretativos, consumir cine erótico se asimilaba tanto a un pasaje y rito hacia la adultez como de aprendizaje para la composición de un horizonte de masculinidad enmarcado dentro de un conjunto de expectativas de género.

La producción y la circulación del cine erótico de Bo y Sarli operó como parte de un entramado sobre el cual bosquejar la construcción de la subjetividad juvenil en los sesenta y setenta, anudándola al carácter de lo prohibido, cuya connotación resultaba atractiva para los sujetos lozanos del momento, y a la expresión de transgresión como un sello de disrupción y rebeldía que reconfiguraba su percepción como adolescentes. 
Ailin Basilio Fabris Las memorias del deseo Aproximaciones al consumo cultural desde los públicos del cine erótico en Argentina (1960-1970)

En este sentido, las décadas de los sesenta y los setenta condensaron un panorama social, cultural y político heterogéneo, diverso, en el que coexistieron ambivalentes expresiones y modulaciones respecto de una vida cotidiana en transición y signada por dinámicas asociadas a ideas de modernidad, tradicionalismo y ruptura. A la distancia, en el abigarrado tejido social urbano tuvieron lugar una serie de dinámicas, prácticas y sentidos signados por la efervescencia política y la intensidad de los planos sociales y culturales respecto de las pautas que regían en materia de sexualidad, sociabilidad y consumo. Lo que para $O$. se revela como un nudo significativo respecto a la representación de su subjetividad sexual y social en 1973, no es sólo el traslado hacia una nueva ciudad y la de eludir los controles para ver el cuerpo erógeno de Isabel Sarli, sino también un punto de inflexión en los anales de la historia social y política local y cuya efeméride se cristalizó en el retorno de Juan Domingo Perón a la presidencia argentina después de casi veinte años de exilio.

Hasta ahora, los relatos han sido pronunciados por varones cuyas experiencias estuvieron nutridas de una amalgama relacional de factores sociales y culturales que rodeaban la experiencia de consumir bienes eróticos. Sin embargo, el testimonio de A., una mujer de 82 años de edad, fractura el andamiaje monocorde masculino que impregnaba la reconstrucción de la experiencia de consumo. Ella y su hijo, C., me relataron sus propias experiencias:

\begin{abstract}
Imagínate, en ese tiempo era una cosa que no era muy vista porque se exhibían sus senos, viste todas esas cosas. Todos procuraban que no fueran los chicos. Pero ellos se escapaban e iban igual. Iban muchos jóvenes, imagínate, quizás en otros cines se exhibían cosas peores pero lo que yo recuerdo es eso. Sé que ella fue la reina de la flor y del perfume en la época de Perón en el año 1951. Ella fue...era muy bonita. Tenía una belleza natural. Todo lo que tenía era de ella, nada quirúrgico ni nada por el estilo. Digamos, muy buen físico (Testimonio de A., mujer, 82 años).
\end{abstract}

El estilo de contar de A. se presenta diferente al empezar a rememorar su experiencia como espectadora. De su voz emana una suerte de dulzura, de embelesamiento con la figura de Isabel Sarli que parece responder menos a una atracción sexual que al reconocimiento de la naturalidad de su cuerpo como medio legítimo de trabajo. No obstante, ello, la idea del cuidado, del velar sobre una niñez que podía verse degradada por visionar este cine, inmediatamente se desplaza a una postura más flexible sobre el tema:

Y después tuvo su gran amor que fue el que la impuso al cine, que fue Armando Bo. Según tengo entendido él era casado, ella no. Nunca quiso dejar a su esposa viste. Ella nunca tuvo hijos naturales, sino que eran adoptados, una nena, que creo que era hija de una mucama de ella. Y para ella, esos chicos eran sus ojos. Pero fue una mujer que se hizo querer porque no tuvo grandes aventuras con otras personas; siempre estuvo con Armando Bo hasta que él se enfermó que ella lo llevó a Norteamérica.

Question, Vol. 1, N. ${ }^{\circ}$ 65, abril 2020. ISSN 1669-6581

Instituto de Investigaciones en Comunicación | Facultad de Periodismo y Comunicación Social | Universidad Nacional de La Plata La Plata | Buenos Aires | Argentina

Página 15 de 24 


\begin{abstract}
Después era una mujer que, no sé, no era... El cine de antes pienso que, no era como el de ahora que tiene muchas más artimañas para hacer una escena a lo mejor, o... Ella si tenía que ir al sur, iba al sur; si tenía que acostarse en la nieve, se acostaba en la nieve; si tenía que tener un tapado, me acuerdo que andaba desnuda- en la nieve; si tenía que desnudarse... Yo vi varias, pero no me acuerdo los títulos. Sí recuerdo la primera que fui a ver Las aguas bajan turbias me parece. Muy buena. Después una cosa que conocimos fue lo que pasaba ahí en los obrajes. Después, mis sobrinos que eran chiquitos viste, como mi cuñado pasaba las películas, iban y se metían un ratito, mi hermana no los dejaba quedarse. Me acuerdo que mi sobrino me decía "¿Por qué no me dejas quedarme? Si son películas científicas" (Testimonio de A., mujer, 82 años).
\end{abstract}

Varios elementos emergen de su relato. Por un lado, la sensibilidad hacia la dimensión maternal y abnegada de la actriz para con sus hijos y su familia. En ese esquema de domesticidad, a los ojos de A, el trabajo femenino cristalizado en Sarli no intercedió con el desarrollo de una familia y un hogar, sino que, por el contrario, su voz le otorga legitimidad a su trayecto biográfico. De acuerdo a Marcela Nari, en las postrimerías decimonónicas y comienzos del siglo $\mathrm{XX}$, se dieron una serie de transformaciones sociales, culturales, materiales y simbólicas que fungieron modelos y presupuestos de maternidad, y bajo los cuales se aglutinaron una serie de expectativas, políticas y lineamientos para las mujeres (2004). Sin embargo, si en el registro social y político de la maternidad se naturalizaba un "instinto maternal" proveniente de la inclinación biológica de la mujer, esto excluía posibles infertilidades y mecanismos burocráticos en torno a la adopción u formas de fertilización y concepción, a organizaciones no heterosexuales y monoparentales. En el caso particular de Sarli, su ejercicio de la maternidad emergió a través de la adopción. De acuerdo a Villalta (2010), durante la década de los sesenta la cuestión de la adopción tuvo como eje central dotar a la niñez de mayor contención parental promoviendo transformaciones y debates en torno a la familia y las leyes de adopción. De esta manera, para A., la maternidad de la actriz no era excluyente de un modelo social y cultural de la maternidad: fuese natural o no, Sarli era madre y simultáneamente trabajadora, asalariada.

En su imaginario, la representación de Bo se conforma en tanto se la liga a la dimensión del adulterio, pero a la vez de la falta de "hombría" para vivir el romance entre ambas figuras. Entonces, la condición de casado más que imponerse como un mandato social impugnable, en el relato de A. se delata un cierto dejo de desilusión:

La gente iba con esas expectativas de verla a ella, pero los jóvenes iban con la esperanza de ver un desnudo que encima mucho no se veía. Acá no se podía ver nada, la censura cortaba; en la época de los militares cortaron todo. Y él (Armando Bo) se dio el gusto que, en una calle de Norteamérica, creo, una calle muy popular de cines, se distribuían dos o tres películas de él; en diferentes cines. Era lo que siempre decía, que allá tuvo éxito, afuera, en el extranjero, acá no porque estaba esa censura que no

Question, Vol. 1, N. ${ }^{\circ}$ 65, abril 2020. ISSN 1669-6581

Instituto de Investigaciones en Comunicación | Facultad de Periodismo y Comunicación Social | Universidad Nacional de La Plata La Plata | Buenos Aires | Argentina

Página 16 de 24 
Ailin Basilio Fabris Las memorias del deseo Aproximaciones al consumo cultural desde los públicos del cine erótico en Argentina (1960-1970)

todavía no se veían esas cosas. Esas cosas aparecían en las revistas, y se consumían; eran muy populares, todo para saber la vida de ellos, de las estrellas (Testimonio de A., mujer, 82 años).

La interpretación de la arista de intimidad de la pareja que se construye en el acto de recordar, aparece mediada por un conjunto de saberes adquiridos de diversas fuentes. Sus palabras parecen extraídas de la prensa gráfica de mayor densidad en números de tiradas y popularidad del siglo XX, como Radiolandia, Antena, Platea, Gente o Siete Días, cuyas editoriales dedicaban una vasta extensión de páginas a la descripción y al escrutinio de la intimidad y la arista profesional de los astros del espectáculo. A lo largo de aquellas páginas, se tramaba el amorío entre Armando Bo e Isabel Sarli, instalando que la pareja estaba casada o vivía un affair, un amorío a costa de la respectiva vida de casado del primero. En el relato de A. como en el $\mathrm{C}$, ambos cribaron la relación entre Bo y Sarli en un sentido supra profesional: eran pareja, matrimonio y vivían un romance. Lo que A. y C. enuncian como una verdad fundada, en realidad se presenta en función de lo que Alessandro Portelli señaló como relatos equivocados o memorias distorsionadas, un conjunto de suposiciones o conjeturas dislocadas de los discursos sobre la veracidad de los hechos. Sin embargo, estas interferencias resultan elementos indiciarios, pinceladas, ya que suponen construcciones de significado cuyas modulaciones revelan disputas por el significado de los eventos y su ponderación colectiva (2017, 1989).

Esta distorsión que florece en el relato de A. nos indica que las narrativas que se elaboran en el relatar abrevan de una serie de pliegues sociales y culturales cuya sedimentación colectiva, lejos de estar concluida, es dinámica, errátil y continúa reescritura. En el corazón de esas reelaboraciones se basculan disputas por el significado y la hegemonía de la memoria, así como la configuración de procesos sociales y culturales más amplios. En el testimonio de C., se relata que todas las películas eran y trataban de lo mismo: "Vos pensa que la Señora estaba casada con Armando Bo y filmaban en Paraguay porque acá estaba todo prohibido, y todas las películas que hacían eran todas las mismas » (Testimonio de R., varón, 55 años).

Al desmenuzar cada testimonio, se percibe que en el ejercicio de evocar la experiencia sobre el concurrir al cine a ver películas de Armando Bo e Isabel Sarli, brotaba un campo semántico compuesto de palabras e imágenes cuyos significantes se reelaboran en el transcurso del narrar. El relato oral supone un desplazamiento constante entre el allá y el ahora, entre lo que pasó y lo que sucede, arrojando luz sobre las tramas y los mecanismos que hacen a la memoria una arena de batalla por sus sentidos, significados y usos. 


\begin{abstract}
Era lindo, todo en esa época era muy lindo. Hoy alguien me diría "Cómo vas a ver esa porquería", pero hoy se vive de otra forma. A mí me gustaba ver esas películas, y más porque tenían paisajes lindos, porque él (Armando) siempre buscaba paisajes lindos, el sur o Misiones. Yo lo único que recuerdo de ella es que siempre decía "¿Qué pretende usted de mí?" en todas las películas. Siempre rodeada de hombres violentos que querían algo de ella, el cuerpo, y querían violarla. Siempre aparecía el héroe que la defendía, pero ya para eso la habían violado [risas]. Ella siempre agradece a Dios lo que hizo en ese tiempo eran películas que... Ella en realidad no tenía vocación de actriz, porque era mala actriz viste, pero era tan bonita; tenía ese cuerpo tan... Y después tenía la humildad que otras mujeres no tenían, a mi parecer (Testimonio de A., mujer, 82 años).
\end{abstract}

Al evocar su experiencia en el cine, A. expide un dejo de nostalgia sobre la significación de asistir a las salas. En compañía de su marido, visionar filmes se convertía en un momento de intimidad de pareja a la vez que de esparcimiento. Estos recuerdos los enmarca dentro de un período sano del cine en el que, en la reescritura de esos eventos, los filmes eran simples, no apelaban a una violencia desmesurada y donde el respeto hacía a una sociabilidad armónica.

\begin{abstract}
No creo que ese cine haya sido visto por gente con plata, que yo recuerde. Por lo general gente de clase media, pero te digo que las chicas iban muy bien vestidas, muy arregladitas. Vos sabes, te cuento, que las parejas iban al cine, pero con la mamá. A las chicas que tenían novio e iban al cine, las acompañaba su mamá, su hermanita o su hermanito. Sola no se salía con el novio. Las parejas iban a ver las películas de Sarli, pero no muchas. En ese tiempo, quizás el novio te ponía la mano en la rodilla, en el hombro, viste, pero no es como los chicos de ahora que se besan en la calle. Esas cosas no pasaban. Además, no te olvides que estaba la madre al lado en la sala (Testimonio de A., mujer, 82 años).
\end{abstract}

Las imágenes que se evocan en el relato de A. dan cuenta de las distintas prácticas y sentidos que rodeaban los consumos culturales, a la vez de como esas experiencias estaban atadas a toda una panoplia de convenciones, disposiciones y estructuras sociales y culturales de género que regían sobre las pautas y los modos de sociabilidad en la segunda mitad del siglo XX. En esos arreglos espaciales en los cuales el género operaba como una lógica activa diferenciada, la administración del cuerpo de hombres y mujeres, pero también de la intimidad de la pareja, en espacios cerrados, participaban de una ritualización de la sexualidad cuya expectativa debía culminar en el matrimonio. Esas representaciones que A. construye sobre el cortejo en las parejas, se encontraban en transición hacia finales de la década de los cincuenta y durante los sesenta (Cosse, 2008). Sin abandonar la carrera hacia el matrimonio, las transformaciones en el entramado de cortejo y noviazgo buscaban afianzar otra sociabilidad y otros sentidos de intimidad más flexibles entre lo público y lo privado. Como ha estudiado esta historiadora, en la década de los sesenta, los hoteles alojamiento y el autocine fueron nuevos modos de resignificar la sexualidad y la sociabilidad de las parejas (Cosse, 2010).

Question, Vol. 1, N. ${ }^{\circ}$ 65, abril 2020. ISSN 1669-6581

Instituto de Investigaciones en Comunicación | Facultad de Periodismo y Comunicación Social | Universidad Nacional de La Plata 
Ailin Basilio Fabris Las memorias del deseo Aproximaciones al consumo cultural desde los públicos del cine erótico en Argentina (1960-1970)

En el relato de A., se anudaron dos dimensiones u elementos yuxtapuestos que, lejos de tener sentidos excluyentes, están articulados. Por un lado, en la representación evocada del consumo de cine erótico, la imagen de Isabel Sarli se reelabora como una armonización entre el trabajo y la domesticidad; su maternidad no entra en conflicto con su condición de mujer asalariada, la cual deviene de la puesta en escena de su cuerpo y la sexualización de sus senos como vector erógeno. Frente a eso, A. se reinterpreta como una espectadora que toma distancia respecto a su propia sexualidad tanto al momento de ver estos filmes, como en el ejercicio de la entrevista. Este desenvolvimiento rígido entre la representación del sexo y del placer y la condición femenina responde menos a interpretaciones de orden biologicista que a las construcciones culturales en torno a la cuestión del placer, la excitación y el goce femenino. Entonces, los marcos de sentido que fundan a las prácticas de consumo de $A$ no relegan completamente una dimensión anclada al erotismo y a la voluptuosidad del cuerpo femenino, sino que las contiene y las canaliza bajo otras formaciones sociales, como el matrimonio o la domesticidad.

Por otro lado, A. no encuentra incompatible el deseo de los adolescentes masculinos por el cuerpo femenino y el acceso a una oferta cultural abocada ello. De este modo, naturaliza ciertos roles y expectativas de género que, de una forma $u$ otra, el hombre debe de cumplimentar en la propia construcción de su subjetividad como masculino viril. La internacionalización y la reificación de una correspondencia entre adolescencia, consumo de cuerpos desnudos y su reencarnación en saberes y prácticas de satisfacción sexual, devienen procesos naturales social y culturalmente avalados en la producción del estatuto de masculinidad.

\section{Consideraciones Finales}

Este trabajo analiza los procesos de consumo cultural del cine erótico de Armando Bo e Isabel Sarli como experiencias e instancias en la elaboración y germinación de disposiciones de género. Al mismo tiempo, reflexiona acerca de las potencialidades de pensar el rol de los consumidores en las configuraciones sociales y culturales de la segunda mitad del siglo XX en Argentina.

En primer lugar, imbrica los estudios de género, la historia de la sexualidad y la historia oral con el objetivo de interrogarse por los posibles derroteros de recuperar la historicidad de las prácticas de consumo y su productividad histórica sobre la sexualidad a través de un repertorio de relatos orales, en los cuales primaron distintas interpretaciones, nociones y experiencias a la hora de significar y habitar el erotismo.

Question, Vol. 1, N. ${ }^{\circ}$ 65, abril 2020. ISSN 1669-6581

Instituto de Investigaciones en Comunicación | Facultad de Periodismo y Comunicación Social | Universidad Nacional de La Plata La Plata | Buenos Aires | Argentina

Página 19 de 24 
Ailin Basilio Fabris Las memorias del deseo Aproximaciones al consumo cultural desde los públicos del cine erótico en Argentina (1960-1970)

En segundo lugar, estas narraciones se ubican en un determinado contexto histórico cuyo entramado se veía horadado por una serie de transformaciones sociales, culturales y políticas que tensionaban al conjunto de la sociedad urbana. Las reconfiguraciones respecto a los modos de atender la sexualidad, la maternidad, la conyugalidad o el cortejo, entre los muchos arreglos tensionados, afectaban la sociabilidad de hombres y mujeres en la década del sesenta y del setenta. El consumo de cine erótico friccionaba la idea de cine como mera práctica lúdica para transfigurarse como un espacio y una materialización para la configuración de una sexualidad, de un aprendizaje, de la adquisición de un saber. Sin embargo, el único relato femenino nos permite trazar o vislumbrar otros senderos sobre cómo las mujeres concibieron y percibieron la actividad y la figura de Isabel Sarli.

En tercer lugar, la dimensión generacional irrigó los modos de reflexionar sobre los motivos que llevaron al consumo. El carácter de la generación les permitió establecer un arraigo concretó que se delineaba como común y trasversal a todos los varones de la época. En esta dirección, entrelazaron su consumo con otras experiencias de su contexto, como la música, la política y lo estudiantil.

Finalmente, estas consideraciones apuntalan la ubicación espacio temporal bajo la cual estas narraciones tomaron forma, tanto en su interpretación sobre su experiencia pasada como en el nivel de lo contemporáneo. En esa distancia, el relato ha ido adquiriendo su propio espesor histórico: aquello que se imponía como un precepto de masculinidad durante la etapa juvenil debía de ratificarse en la oralidad para demarcar una diferencia y una distancia respecto de la autopercepción del yo que se narra en el presente. En la actualidad, el relatar estas experiencias colaboró con nuevas formas de reactualizar y revalorizar el papel que el cine erótico detentó y movilizó durante la segunda mitad del siglo XX.

Los relatos orales que hemos analizados nos permitieron alumbrar las diversas formas en las que fueron pensadas el cuerpo, la sexualidad y el género en un determinado momento histórico. En este sentido, las operaciones que involucran el consumo cultural del cine en perspectiva histórica delinearon algunas coordenadas respecto a los modos de sentir, vivir y percibir la sexualidad, las relaciones sociales y el género en un determinado momento histórico que, lejos de agotarse allí, se transfiguraron a lo largo del tiempo a través de diversos soportes, públicos y consumos.

En el abigarrado entramado de la década de los sesenta, el cine erótico presentaba una configuración y representación discursiva relacional entre cuerpo, género, placer y sexualidad con pretensiones de trascender e interpelar a los espectadores de cine a fin de disputar y negociar ciertas concepciones, nociones y sentidos sobre el lugar de la sexualidad y el goce en el esquema de interacción social de los sujetos.

Question, Vol. 1, N. ${ }^{\circ}$ 65, abril 2020. ISSN 1669-6581

Instituto de Investigaciones en Comunicación | Facultad de Periodismo y Comunicación Social | Universidad Nacional de La Plata La Plata | Buenos Aires | Argentina

Página 20 de 24 
Ailin Basilio Fabris Las memorias del deseo Aproximaciones al consumo cultural desde los públicos del cine erótico en Argentina (1960-1970)

\section{Referencias bibliográficas}

Appadurai, A. (1991). La vida social de las cosas. Perspectiva cultural de las mercancías, Ciudad de México: Grijalbo.

Barthes, R. (2002). El placer del texto, Siglo XXI Editores, Buenos Aires, 2008.

Bjerg, M. (2012). El viaje de los niños. Inmigración, infancia y memoria en la Argentina de la Segunda Posguerra, Ciudad de Buenos Aires: Edhasa.

Bourdieu, P. (2000). La dominación masculina, Barcelona: Anagrama.

Braslavsky, E., Drajner Barredo, T., \& Pereyra, B. (2013). Insaciable (Armando Bo, 1974), entre la liberación sexual y el castigo moralizante", Imagofagia, (8), 1-29.

Caldo, P. (2013). Las cocineras de La Capital. Lectoras, amas de casa, ecónomas, consumidoras y saberes femeninos: una experiencia rosarina (1930-1945), Sociedad y Economía, (24), 47-70.

Cammarota, A. (2014). Somos bachiyeres. Juventud, cultura escolar y peronismo en el Colegio Nacional mixto de Morón (1949-1969), Ciudad de Buenos Aires: Biblos.

Capalbo, A., \& Valdéz, M. (2004). Amor constante más allá de la pantalla. Armando Bo e Isabel Sarli en Columbia Pictures. En España, C. (Dir.). Cine Argentino. Modernidad y Vanguardia, 1957-1983,Tomo II, Buenos Aires: Fondo Nacional de Las Artes.

Cosse, I. (2010). Pareja, sexualidad y familia en los años sesenta, Buenos Aires: Siglo XXI Editores.

Cosse, I. (2008). Del matrimonio a la pareja: continuidades y rupturas en el modelo conyugal en Buenos Aires (1960-1975), Anuario IEHS, vol. 23, 2008b, pp. 431-458

D’Antonio, D. (2015). Paradojas del género y la sexualidad en la filmografía durante la última dictadura militar argentina, Estudios Feministas, 23 (3), 913-937.

De Grazia, V. \& Furlough, E. (1996). The Sex of Things. Gender and Consumption in Historical Pers-

pective. Berkeley: University of California Press.

Drajner Barredo, T. (2016). ¿Cosificación o uso político? Carne de Armando Bo-Isabel Sarli_Imagofagia,(14), 1-27

Dussaillant, J. (2011). Las reinas del estado: Consumo, grandes tiendas y mujeres en la modernización del comercio en Santiago, Santiago de Chile: Ediciones UC.

Elena, E. (2011). Dignifying Argentina: Peronism, citizenship, and mass consumption, Pittsburgh: University of Pittsburgh Press.

Felitti, K. (2012). La revolución de la píldora. Sexualidad y política en los sesenta, Buenos Aires: Edhasa. 
Ailin Basilio Fabris Las memorias del deseo Aproximaciones al consumo cultural desde los públicos del cine erótico en Argentina (1960-1970)

García Canclini, N. (1999). El consumo cultural: una propuesta teórica", en Consumo Cultural en América Latina, Santa Fe de Bogota: Convenio Andrés Bello, 26-49.

Guy, D. (2018). Producción, ventas y consumo: reflexiones sobre el papel del género en las tiendas grandes de Buenos Aires, 1883-1930", Descentrada, 2 (1), 1-16.

Hollows, J. (2000). Feminism, Femininity and Popular Culture. Manchester: Manchester University Press.

Isabel Sarli prende fuego los cines (6 de octubre de 1971). Diario Crónica Jelin, E. (2002). Los trabajos de la memoria, Madrid: Siglo XXI Editores.

Matencón, A. R. (2002). Los estudios sobre consumo cultural en México. En Mato, D. (Coord.). Estudios y otras prácticas intelectuales Latinoamericanas en Cultura y Poder. (pp.255264). Caracas: Consejo Latinoamericano de Ciencias Sociales y CEAP, FACES, Universidad Central de Venezuela.

Mantecón, A. R. (2008). Mercados, políticas y públicos: la reorganización de las ofertas y los consumos culturales, Alteridades, 18 (36), 23-31.

Manzano, V. (2017). La era de la juventud en Argentina. Cultura, política y sexualidad desde Perón hasta Videla, Ciudad de Buenos Aires, Fondo de Cultura Económica.

Milanesio, N. (2014). Cuando los trabajadores salieron de compras. Nuevos consumidores, publicidad y cambio cultural durante el primer peronismo, Buenos Aires: Siglo XXI.

Mitidieri, G. (2018). Entre modistas en París y costureras del país. Espacios de labor, consumo y vida cotidiana de las trabajadoras de la aguja, Buenos Aires 1852-1862, Trashumante, (12), 8-29.

Parrini, R. \& Brito, A. (2014). La memoria y el deseo. Estudios gay y queer en México, México D. F.: Universidad Autónoma de México.

Pérez, I. (2017). Consumo y género: una revisión de la producción historiográfica reciente sobre América Latina en el Siglo XX, Historia Crítica, (65), 29-48.

Pite, R. (2016). La mesa está servida. Doña Petrona C. de Gandulfo y la domesticidad en la Argentina del siglo XX. Buenos Aires: Edhasa.

Portelli, A. (1981). The Peculiarities of Oral History, History Workshop, 12, pp. 96-107

Portelli, A. (1989). Historia y memoria: la muerte de Luigi Trastulli. Historia y fuente oral, 5-32.

Rocchi, F. (1998). Consumir es un placer: la industria y la expansión de la demanda en Buenos Aires a la vuelta del siglo pasado", Desarrollo Económico, 37 (148), 533-558.

Sexacional (16 de febrero de 1969). La gaceta de espectáculos.

Simonetto, P. (2016). La moral institucionalizada. Reflexiones sobre el Estado, las sexualidades y la violencia en la Argentina del siglo XX". e-l@tina. Re-vista Electrónica de Estudios Latinoamericanos, $14(55), 1-22$.

Question, Vol. 1, N. ${ }^{\circ} 65$, abril 2020. ISSN 1669-6581

Instituto de Investigaciones en Comunicación | Facultad de Periodismo y Comunicación Social | Universidad Nacional de La Plata La Plata | Buenos Aires | Argentina

Página 22 de 24 
Ailin Basilio Fabris Las memorias del deseo Aproximaciones al consumo cultural desde los públicos del cine erótico en Argentina (1960-1970)

Simonetto, P. (2018). Pagar para ser hombre. Prácticas y sentidos de la compra de sexo en los testimonios judiciales de trabajadores. Provincia de Buenos Aires 1936-1960, Revista Historia y Justicia, Recuperado de http://journals.openedition.org/rhi/1275

Scheinkmann, L. (2017). Dulces consumidores. La construcción publicitaria del consumo femenino e infantil de golosinas en las primeras décadas del siglo XX en la Argentina, Revista Meridional, (9), 145-190.

Schwarzstein, D. (2002). Fuentes orales en los archivos: desafíos y problemas, Historia, Antropología y Fuentes Orales, (27), pp. 167-177.

Tinsman, H. (2016). Se compraron el modelo: consumo, uva y la dinámica transnacional: Estados Unidos y Chile durante la Guerra Fría, Santiago de Chile: Ediciones Universidad Alberto Hurtado.

Trentmann, F. (2004). Beyond Consumerism: New Historical Perspectives on Consumption, Journal of Contemporary History, 39 (3), 373-401.

Williams, L. (2002). Screening sex, Duke University Press, 2008.

Villalta, C. (2010). Imitar a la naturaleza. La adopción de niños en los años '60: entre ficciones legales y prácticas consuetudinarias. En Cosse, I; Fellit, K, \& Manzano, V. (Edit.). Los 60 de otra manera. Vida cotidiana, género y sexualidades en la Argentina (pp. 89-129). Buenos Aires: Prometeo

Wortman, A. (2012). Consumos culturales en Argentina, Alteridades, 22 (44), 11-21.

Wortman, A. (2015). Consumos culturales en Buenos Aires: una aproximación a los procesos sociales contemporáneos, Documentos de Trabajo, (73), Buenos Aires: Instituto de Investigaciones Gino Germani.

Wortman. A. (Coord.). (2018). Un mundo de sensaciones. Sensibilidades e imaginarios en producciones y consumos culturales argentinos en el siglo XXI. Ciudad de Buenos Aires: Instituto de Investigaciones Gino Germani y Consejo Latinoamericano de Ciencias Sociales.

\section{Entrevistas}

R., masculino, 72 años

C., masculino, 55 años

H., masculino, 61 años

M., masculino, 54 años

O., masculino, 61 años

A., mujer, 82 años 
Ailin Basilio Fabris Las memorias del deseo Aproximaciones al consumo cultural desde los públicos del cine erótico en Argentina (1960-1970) 